\title{
Model Sistem Monitoring Dan Kendali Pintu Air Otomatis Berbasis Arduino dan LabView
}

\author{
Abdurahman \\ Prodi Teknik Elektro FT UNPAM \\ JIn. Puspiptek Raya No 46 Buaran, Tangerang Selatan 15310 INDONESIA \\ abdurahman00943@gmail.com
}

\begin{abstract}
ABSTRAK
Model sistem ini hanyalah miniatur sistem dan akan berubah pemodelannya sesuai dengan tempat dimana aplikasi ini diterapkan, akan tetapi tidak keluar dari algoritma sistem yang telah dirancang. Dengan mengunakan sistem loop tertutup, masukan dari sensor akan berpengaruh terhadap keluaran dari kontrol motornya. Seolah-olah motor tahu ketika ketinggian air mencapai batas tertentu dia akan berputar untuk menggerakkan pintu naik atau turun sesuai masukan sensor dan kontroler yang sudah diprogram. Model sistem ini berguna untuk mengatur aliran air di bendungan berdasarkan ketinggian. Dengan adanya model sistem ini, ketinggian air dapat dikontrol secara otomatis dan manual. Jadi, kita tidak perlu khawatir akan volume air yang meningkat. Model sistem ini dibuat berbasis labview dengan arduino sebagai kontroler, sensor ultrasonik HC-SR04 sebagai pembaca ketinggain air dan ketinggian pintu air. Motor stepper+ULN2003A driver sebagai aktuator untuk menggerakkan pintu air naik dan turun pada ketinggian $6 \mathrm{~cm}, 16 \mathrm{~cm}$ dan $26 \mathrm{~cm}$ pada keadaan sistem otomatis
\end{abstract}

Kata kunci : labview, arduino, sensorultrasonik, motor stepper, otomatis danmanual

\section{ABSTRACT}

This system is simply a miniature model of the system and will change modeling in accordance with the place where the application is implemented, but not out of the algorithm of the system that has been designed. By using the closed-loop system, the input from the sensor will affect the output of the motor control. As if the motor out when the water level reaches a certain point he will rotate to move the door up or down in accordance input sensors and controllers are programmed. Model is a useful system to regulate the flow of water in the dam based on the height. With the model of this system, the water level can be controlled automatically and manually. So, we do not have to worry about increased water volume. The model is made based labview with arduino as a controller, the HC-SRO4 ultrasonic sensor as the reader height water and the height of the sluice. ULN2003A stepper motor + driver as an actuator to move up and down the water gates at a height of $6 \mathrm{~cm}, 16$ $\mathrm{cm}$ and $26 \mathrm{~cm}$ on the state of the automated system.

Keywords: labview, arduino, ultrasonic sensor, stepper motors, automatic and manual

\section{PENDAHULUAN}

D intu air merupakan gerbang dimana air yang mengalir pada bendungan atau waduk dapat dikontrol volumenya. Dengan adanya pintu air keadaam volume air dapat dimonitoring agar tidak berlebih dan bisa terhindar dari situasi yang tidak diinginkan seperti banjir dan jebolnya tanggul bendungan. Korelasinya kelebihan volume air yang berlebih mengakibatkan debit air dapat meningkat. Dengan adanya pintu air, secara bertahap air yang berlebih dapat dikontrol sesuai dengan volume air yang ada di bendungan.

Model sistem ini dibuat menggunakan sensor ultrasonik HC-SR04 sebagai pengukur 
ketinggain air dan pintu air. Sedangkan untuk aktuatornya menggunakan motor stepper, agar pintu air bisa bergerak naik dan turun. Pada keadaan sebenarnya motor stepper dapat diganti dengan motor tiga phase sesuai kebutuhan.

Untuk sistem pembangun penulis menggunakan LabVIEW 2014. Software ini dianggap powerfull dan memiliki user interface yang mudah dibuat.

Model sistem monitoring ini dibuat untuk mngetahui prediksi apa saja yang akan dihadapi ketika sistem monitoring sebenarnya direalisasikan.
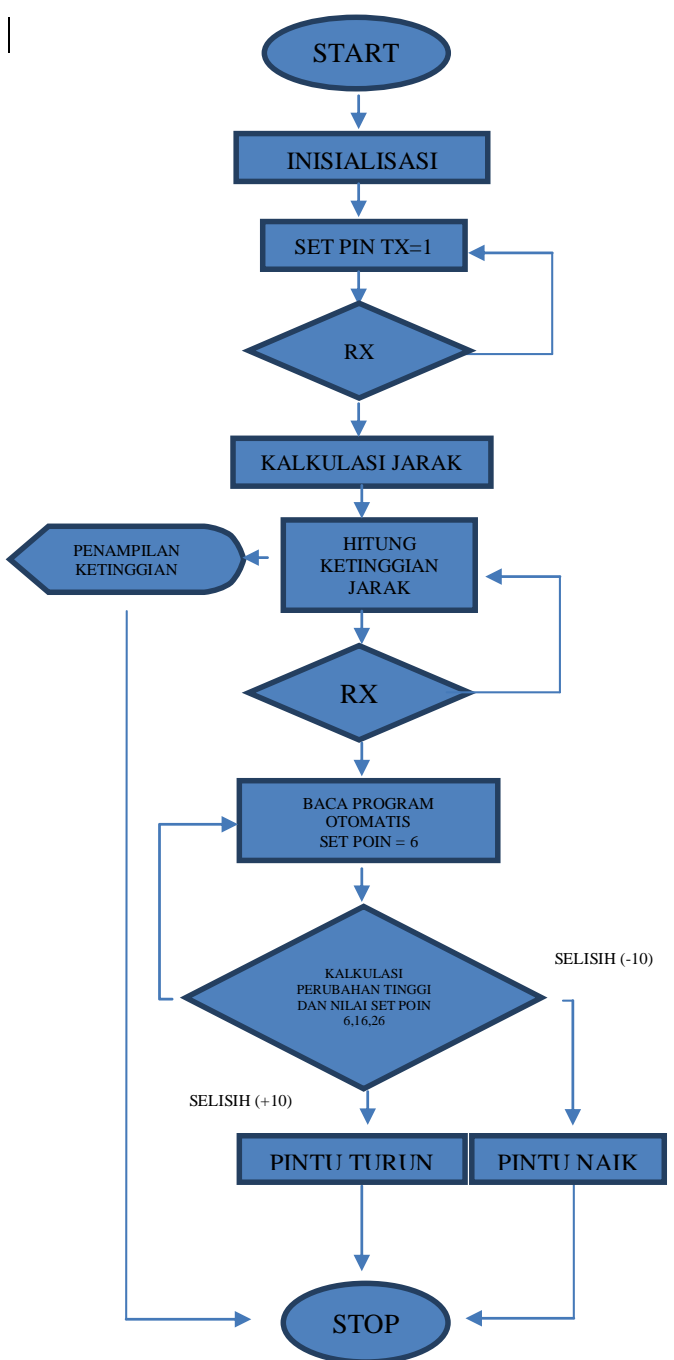

Gambar 1. Diagram alir sistem

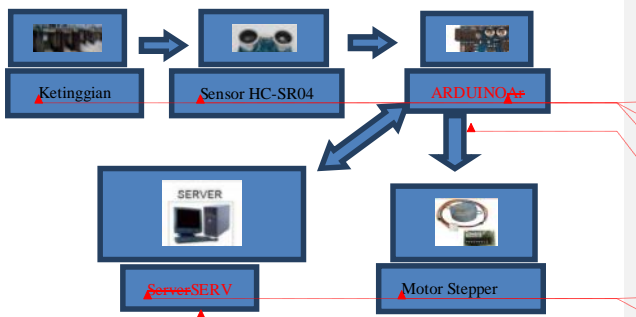

Gambar 2. Blok diagam sistem

Formatted: Font: $6 \mathrm{pt}$
Formatted: Font: $6 \mathrm{pt}$
Formatted: Font: $6 \mathrm{pt}$
Formatted: Font: $3 \mathrm{pt}$
Formatted: Font: $6 \mathrm{pt}$
Formatted: Font: $6 \mathrm{pt}$

Tujuan penelitian ini adalah untuk membuat model sistem monitoring yang bekerja secara otomatis dan manual berdasarkan ketinggian air. Dalam keadaan otomatis pintu air dapat naik dan turun pada ketinggian $6 \mathrm{~cm}, 16$ $\mathrm{cm}$ dan $26 \mathrm{~cm}$. Penulis melakukan perbandingan satuan panjang antara model dan keadaan sebenaenya, yaitu ketinggian $6 \mathrm{~cm}$ pada model, berarti 6 meter pada ketinggian sebenarnaya. Jadi, perbandingannya adalah $1 \mathrm{~cm}: 1 \mathrm{~m}$.

\section{TEORI}

\section{Mikrokontroler}

AVR adalah sebuah mikrokontroler yang dibuat dengan menggunakan arsitektur Harvard dimana data dan program disimpan secara terpisah sehingga sangat baik untuk sebuah sistem terbenam di lapangan karena terlindungi dari interferensi yang dapat merusak isi program. Salah satu mikrokontroler keluarga AVR yang dipergunakan pada penelitian ini yaitu ATmega328.

\section{Arduino}

Arduino adalah platform pembuatan prototype elektronik yang bersifat opensource hardware yang berdasarkan pada perangkat keras dan perangkat lunak yang fleksibel dan mudah digunakan

Shield adalah sebuah papan yang dapat dipasang diatas arduino board untuk menambah kemampuan dari arduino board. Bahasa pemrograman arduino adalah bahasa pemrograman yang umum digunakan untuk membuat perangkat lunak yang ditanamkan pada arduino board. Bahasa pemrograman arduino mirip dengan 
bahasa pemrograman $\mathrm{C}++$. Namun pada penelitian ini penulis menggunakan bahasa graphical dengan LabView sebagai media pemrogramnya.

\section{LabView}

LabVIEW adalah produk dari National Instruments yang berupa software pengembangan program aplikasi dan hardware input-output untuk keperluan akusisi dan pengendalian. Perangkat lunak (software) ini dapat dijalankan pada sistem operasi 20Linux, Unix, Mac OS $X$ dan Windows. Berbeda dengan pemograman berbasis teks dimana instruksi-instruksi menentukan eksekusi program pada sistem kendali, LabVIEW merupakan pemograman aliran data dimana aliran data menentukan eksekusi dari program. Perangkat lunak LabVIEW merupakan sebuah bahasa pemograman graphicalyang menggunakan simbol (ikon) untuk membuat aplikasi.

\section{Tipe Data}

Dalam membuat aplikasi VIs, harus diperhatikan tipe data tiap simbol agar data flowdapat berjalan semestinya. Tipe data yang tersedia yaitu numerik, boolean dan string. Tipe data dari sebuah simbol dapat diketahui dari warna node atau warna kabel ketika dihubungkan ke simbol lainnya. Untuk tipe data numerik ditandai dengan warna oranye (untuk bilangan float) atau biru (untuk bilangan integer), tipe data boolean ditandai dengan warna hijau dan tipe data stringditandai dengan warna merah muda.

\section{Motor Stepper}

Motor stepper adalah perangkat elektromekanis yang bekerja dengan mengubah pulsa elektronis menjadi gerakan mekanis diskrit. Motor stepper bergerak berdasarkan urutan pulsa yang diberikan kepada motor. Karena itu, untuk menggerakkan motor stepper diperlukan pengendali motor stepper yang membangkitkan pulsa-pulsa periodik. Penggunaan motor stepper memiliki beberapa keunggulan dibandingkan dengan penggunaan motor DC biasa

\section{Kontrol Loop Tertutp}

Pada perancangan, alat ini menggunakan sistem kontrol close loop atau sistem kontrol loop tertutup, yaitu sistem kontrol yang sinyal keluarannya mempunyai pengaruh langsung pada aksi pengontrolan sistem. Jadi, nilai keluaran pada sistem kontrol ini memiliki nilai umpan balik yang berpengaruh pada pengontrolan sistem. Nilai umpan balik tersebut akan terus dibaca sampai pengontrolan sistem berhasil atau memenuhi keadaan yang diinginkan.

\section{METODOLOGI}

\section{Bahan dan Alat}

Spesifikasi alat secara keseluruhan ditentukan terlebih dahulu sebagai acuan dalam perancangan selanjutnya. Spesifikasi alat yang direncanakan yaitu:

- Mengunakan Arduino Uno sebagai pusat kendali sistem.

- Menggunakan sensor Ultrasonik HCSR04 sebagai pendeteksi ketinggian air dan ketinggian dan ketinggian pintu air.

- Menggunakan motor stepper 28BYJ dengan driver ULN203A sebagai aktuator (penggerak pintu air naik dan turun).

- Mengggunakan catu daya 5 volt dc.

Menggunakan LabVIEW dengan AddOn MakerHub sebagai Software pembangun

\section{Tata Kerja}

Untuk pertama kali dihidupkan, program menginisialisasi port-port yang terhubung antara mikrokontroler dan pin pin motor stepper. Penulis menggunakan motor stepper bipolar dengan half stepp. Pada tabel 3.1 terdapat 4 kabel yang terhubung dengan motor stepper yaitu Orange, Yellow, Pink and Blue. Untuk dapat berputar satu putaran mikrokontroler harus mengirim 8 kali perubahan bit pada register.

Perhatikan Tabel 1, merupakan perubahan nilai bit pada register yang digunakan untuk memutar motor stepper. Bit pertama merupakan bit yang perubahannya akan berpengaruh pada kabel warna biru pada motor stepper. Perubahan tersebut yaitu dengan nilai "1" 
untuk high yang berarti tegangan 5 volt dan nilai "0" untuk low untuk tegangan 0 volt. Begitu pula dengan bit ke-2 (pink), bit ke-3 (yellow) dan bit ke-4 (orange).

Tabel 1. Perubahan bit pada register

\begin{tabular}{llllll}
\hline \multirow{2}{*}{ No } & Orange & Yellow & Pink & Biru & $\begin{array}{l}\text { Dalam } \\
\text { desimal }\end{array}$ \\
\cline { 2 - 6 } $\mathbf{1}$ & 0 & 0 & 0 & 1 & 1 \\
\hline $\mathbf{2}$ & 0 & 0 & 1 & 1 & 3 \\
\hline $\mathbf{3}$ & 0 & 0 & 1 & 0 & 2 \\
\hline $\mathbf{4}$ & 0 & 1 & 1 & 0 & 6 \\
\hline $\mathbf{5}$ & 0 & 1 & 0 & 0 & 4 \\
\hline $\mathbf{6}$ & 1 & 1 & 0 & 0 & 12 \\
\hline $\mathbf{7}$ & 1 & 0 & 0 & 0 & 8 \\
\hline $\mathbf{8}$ & 1 & 0 & 0 & 1 & 9 \\
\hline
\end{tabular}

Pada baris nomor 1 dan nomor 2 terdapat berubahan bit yaitu pada bit ke-1 (biru) dan bit ke-2 (pink). Pada bit ke-2 dari nilai "0" menjadi " 1 " sedangkan untuk bit ke1 bernilai tetap yaitu "1". Perubahan tersebut menandakan bahwa rotor yang bergerak dari kumparan yang terhubung dengan kabel warna biru dan sekarang berada diantara kumparan yang terhubung dengan kabel warna biru dan pink. Kemudian baru pada baris ke- 3 kabel warna biru bernilai "0" dan rotor bergerak menuju kumparan yang terhubung dengan warna pink. Begitu seeterusnya program akan terus berjalan sampai power mati.

Pada set poin awal ditentukan dengan nilai 6 dan program mulai bekerja apabila nilai ketinggian lebih dari 5, penulis analogikan angka 5 dan 6 dalam $\mathrm{cm}$. Tinggi pintu air pertama kali diseting pada ketinggian $4 \mathrm{~cm}$ dan ketingian awal bisa diseting sesuai keinginan.

- Ketika tinggi air bergerak dari angka 6 ke angka 16, program akan mendapatkan selisih $16-6=10$ yang berarti pintu air akan bergerak turun sekitar $1 \mathrm{~cm}$ dan angka 16 akan mengganti nilai SET POINT menjadi 16.

- Ketika tinggi air bergerak dari angka 16 ke angka 26, program akan mendapatkan selisih $26-16=10$ yang berarti pintu air akan bergerak turun sekitar $1 \mathrm{~cm}$ dan angka 26 akan mengganti nilai SET POINT menjadi 26.

- Ketika tinggi air bergerak dari angka 26 ke angka 16, program akan mendapatkan selisih $16-26=-10$ yang berarti pintu air akan bergerak naik sekitar $1 \mathrm{~cm}$ dan angka 26 akan mengganti nilai SET POINT menjadi 16.

- Ketika tinggi air bergerak dari angka 16 ke angka 6, program akan mendapatkan selisih $6-16=-10$ yang berarti pintu air akan bergerak turun sekitar $1 \mathrm{~cm}$ dan angka 16 akan mengganti nilai SET POINT menjadi 6 .

Begitu seterusnya program akan berjalan dan akan berhenti sampai power dimatikan.

Pengujian alat secara keseluruhan bertujuan untuk mengetahui apakah alat sudah dapat bekerja sesuai perencanaan. Peralatan yang digunakan :

- Arduino

- Labview software

- Sensor ulatrasonik HC-SR04

- Motor stepper + ULN2003A driver

- Catu daya

Langkah-langkah pengujian:

- Alat dirangkai sesuai perencanaan seperti yang telah dijelaskan pada bagian sebelumnya

- Kolom setpoint diisi dengan angka 6

- Tinggi pintu air diset pada ketinggian $4 \mathrm{~cm}$

\section{HASIL DAN PEMBAHASAN}

Setelah alat dipasang sesuai dengan rangkaian, maka didapat hasil sebagai berikut :

- Pertama kali alat dihidupkan alat dalam keadaan standby dan dalam mode OTOMATIS

- Pada saat ketinggian air mencapai $16 \mathrm{~cm}$, maka pintu air akan turun dari 4 $\mathrm{cm}$ maenjadi $3 \mathrm{~cm}$ 
- Pada saat ketinggian air mencapai $26 \mathrm{~cm}$, maka pintu air akan turun dari 4 $\mathrm{cm}$ maenjadi $2 \mathrm{~cm}$

- Pada saat ketinggian air turun dari 26 $\mathrm{cm}$ menjadi $16 \mathrm{~cm}$, maka pintu air akan naik dari $2 \mathrm{~cm}$ menjadi $3 \mathrm{~cm}$

- Pada saat ketinggian air turun dari 16 $\mathrm{cm}$ menjadi $6 \mathrm{~cm}$, maka pintu air akan naik dari $3 \mathrm{~cm}$ menjadi $4 \mathrm{~cm}$

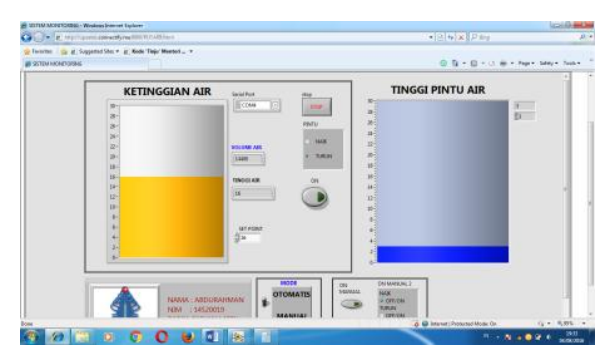

Gambar 3. Sistem pada saat ketinggian air $16 \mathrm{~cm}$

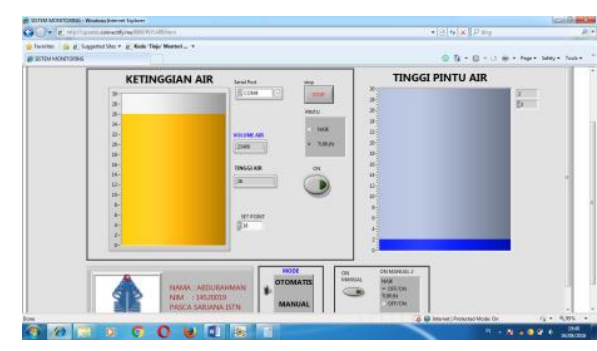

Gambar 4. Sistem pada saat ketinggian air $26 \mathrm{~cm}$

Seperti yang penulis katakan sebelumnya bahwa alat ini merupakan model dari keadaan sebenarnya. Untuk itu penulis merangkai pula alat dengan keadaan sebenarnya. Ada beberapa komponen alat dan sebagian blok pemrograman yang berbeda, yaitu pada motor dan programnya. Spesifikasi alat dengan sistem sebenarnya yaitu:

- Inverter tipe ATV12HU 15M2 dari Schneider

- Zelio Relay dari Schneider

- Motor 3 phasa (jenis dan torsi disesuaikan dengan kebutuhan)

- Arduino Uno

- Menggunakan Labview Maker Hub sebagai software pembangun

- Catu daya DC dan AC
Pada model, motor yang digunakan menggunakan motor stepper 28BYJ dengan driver ULN203A sedangkan pada sistem sebenarnya, dapat menggunakan motor 3 phase (kekuatan motor disesuaikan dengan sistem) dengan inverter tipe ATV12HU 15M2 dan relay dari Schneider. Sedangkan rangkaian dan program seperti terlihat pada gambar dibawah ini.

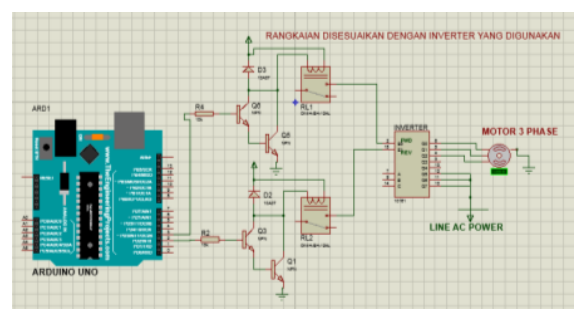

Gambar 5. Rangkaian motor 3 pahse dengan arduino

Sedangkan untuk program kendali motor dapat menggunakan progrsm sederhana dengan blok diagram dibawah ini

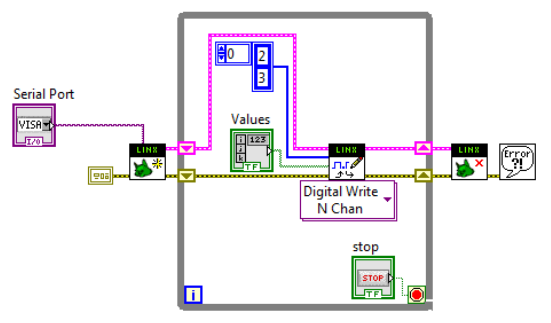

Gambar 6 Blok diagram motor 3 phase

Keterangan :

- Pin 2 pada arduino terhunung dengan relay FWD (Forwad) naik

- Pin 3 pada arduino terhubung dengan relay REV (Reverse) turun

Sedangkan untuk kecepatan motor bisa diatur lewat settingan inverter atau pwm pada Arduino

Sensor Ultrasonik HC-SR04 digunakan untuk mengetahui ketinggian air dan berapa ketinggian pintu air yang telah terbuka. 
Perhatikan Gambar 7, untuk mengukur tinggi pintu air :

- Pin Trigger pada sensor ultrasonik HCSR04 terhubung dengan pin 9 pada Arduino

- Pin Echo pada sensor ultrasonik HCSR04 terhubung dengan pin 8 pada Arduino

Untuk mengukur tinggi air :

- Pin Trigger pada sensor ultrasonik HC-SR04 terhubung dengan pin 7 pada Arduino

- Pin Echo pada sensor ultrasonik HCSR04 terhubung dengan pin 6 pada Arduino

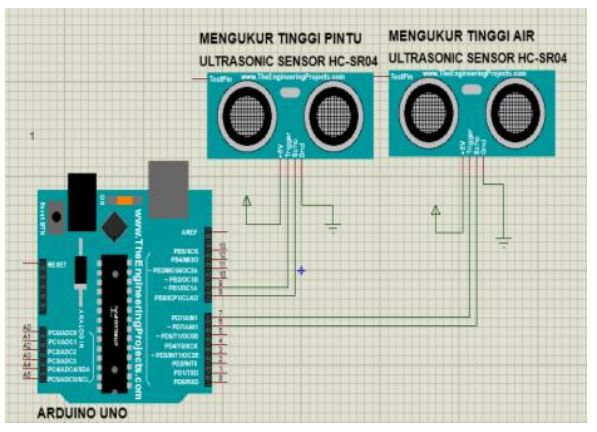

Gambar 7Arduino dan Sensor Ultrasonik HC-SR04

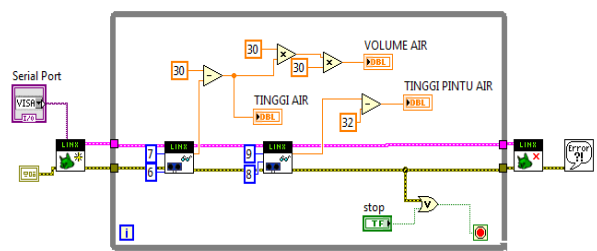

Gambar 8Blok diagram sensor ultrasonik HC-SR04

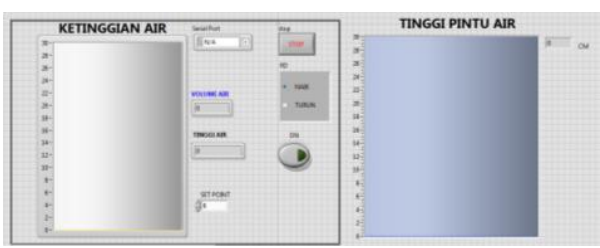

Gambar 9Front panel sensor ultrasonik HC-SR04

Untuk pertama kali dihidupkan program menginisialisasi port-port yang terhubung antara mikrokontroler dan sensor ultasonik HC-SR04. Setelah rangkaian dan program sudah singkron, pin Triger(TX) akan memancarkan gelombang ultrasonik dengan frekuensi $40 \mathrm{KHz}$ kemudian pin Echo(RX)menangkap hasil pantulan gelombang ultrasonik yang mengenai suatu objek dan begitu seterusnya secara berulang.

Waktu tempuh gelombang ultrasonik dari pemancar hingga sampai ke penerima sebanding dengan 2 kali jarak antara sensor dan bidang pantul. Hasil perhitungan jarak tersebut akan mengurangi angka 30 yang ada padaregister dan kemudian ditampilkan di monitor. Hasil pengurangan tersebut merupakan ketinggian air dan ketinggian pintu air.

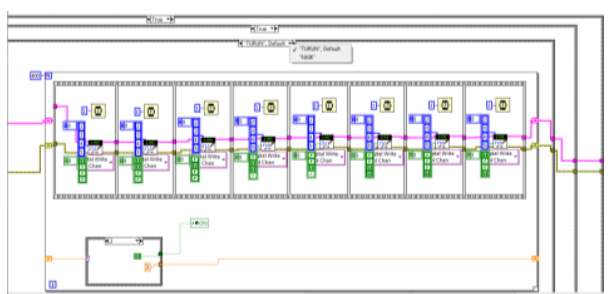

Gambar 10Blok diagram pintu air turun

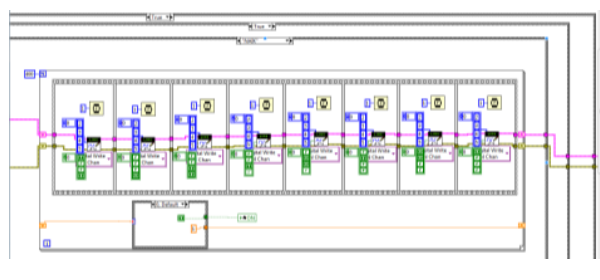

Gambar 11 Blok diagram pintu air naik

\section{KESIMPULAN}

Setelah dilakukan pengujian terhadap alat sesuai dengan rancangan, maka penulis menyimpulkan:

- Sensor ulatrasonik HC-SR04 dapat membaca ketinggain air dan ketinggian pintu air dari 0 (nol) sampai $30 \mathrm{~cm}$

- Pada keadaan otomatis, ketinggian pintu air diset pada $4 \mathrm{~cm}$, dan setpoint 6 , 
$\checkmark$ Ketika tinggi air naik dari $0 \mathrm{~cm}$ ke 16 $\mathrm{cm}$, pintu air turun dari $4 \mathrm{~cm}$ ke 3 $\mathrm{cm}$.

$\checkmark$ Ketika tinggi air naik dari $16 \mathrm{~cm}$ ke $26 \mathrm{~cm}$, pintu air turun dari $3 \mathrm{~cm}$ ke 2 $\mathrm{cm}$.

$\checkmark$ Ketika tinggi air turun dari $26 \mathrm{~cm} \mathrm{ke}$ $16 \mathrm{~cm}$, pintu air naik dari $2 \mathrm{~cm}$ ke 3 $\mathrm{cm}$.

$\checkmark$ Ketika tinggi air turun dari $16 \mathrm{~cm}$ ke $6 \mathrm{~cm}$, pintu air naik dari $3 \mathrm{~cm}$ ke 4 $\mathrm{cm}$.

- Pada keadaan manual, pintu air dapat digerakkan naik dan turun sesuai keinginan

\section{UCAPAN TERIMAKASIH}

Dalam penulisan ini penulis dibantu oleh orang-orang yang menurut penulis berkompeten dalam bidangnya, oleh karena itu penulis mengucapkan terima kasih kepada beliau-beliau, diantaranya:

1) Prof. Dr. Masbah R.T. Siregar , APU., selaku Kaprodi Pasca Sarjana Teknik Elektro, ISTN

2) Dr. Ir. Djoko Hari Nugroho, MT., selaku Dosen Pembimbing Tesis.

3) Syaiful Bakhi, Ph.D , selaku Kaprodi Teknik Elektro UNPAM

4) serta personal yang mendukung terlaksananya penelitian dan penulisan.

\section{DAFTAR PUSTAKA}

[1] Nguyen, Cuong Hong. Mobile and Wireless Technology for Measurement and Monitoring. Telemark University College : Faculty of Technology, 2013.

[2] Schwartz, Marco dan Oliver Manickum. Programming Arduino with LabVIEW. BIRMINGHAM - MUMBAI : Packt Publishing Ltd, 2015

[3] Halvorsen, Hans-Petter M.Sc. 2015. LabView Web Service. Telemark University College Faculty of Technology : Department of Electrical Engineering

[4] Daniel K. Fisher dan Ruixiu S., 2013, An Expensive open-source ultrasonic sensing system for monitoring liquid level, Agric Eng Intl CIGR Journal, Vol.15, No 14, December

[5] Naveenkumar R., Prasad Krisna, Low Cost Data Acquisition and Control using Arduino prototyping Platformmed LabVIEW', International Journal of Science and Research (IJSR), India online ISSN, 2319-7064

[6] Swarna Prabha Jena, Shanaz Aman, Rupanita Das, Computerized Green House Data Acquisition System Using Arduino with LabVIEW, International Journal of Advenced Research in Electrical, Electronics and Instrumentation Engineering, Vol. 4, Issue 4, April 2015, ISSN : 2320-3765.

[7] Joshi1. N. P., P.V.Patel."LabVIEW and Web-Server based Human Body Monitoring System". International Journal of Advenced Research in Electrical, Electronics and Instrumentation Engineering. University, Rajkot, Gujarat, India, 2014

[8] Tool For Smart Mind.Learning Remote Control Framework - ADD-ON for LabVIEW. Tool For Smart Mind, 2013.

[9] Syahwil, Muhammad.Panduan Mudah Simulasi dan Praktek Mikrokontroler Arduino. Yogyakarta : CV ANDI OFFSET, 2013.

[10]Kadir, Abdul . Panduan Praktis Mempelajari Aplikasi Mikrokontroler dan Pemrogramannya menggunakan Arduino. Yogyakarta : CV ANDI OFFSET, 2013 